\title{
Brazilian Reflexion: Papers Published in One Semester of Covid-19
}

\author{
Raw MC and Dini AP* \\ Nursing School, University of Campinas, Brazil
}

*Corresponding author: Ariane Polidoro Dini, Nursing School, University of Campinas, São Paulo, Brazil, Email: adini@unicamp.br

\section{Research Article}

Volume 4 Special Issue 1

Received Date: September 25, 2020

Published Date: October 29, 2020

DOI: $10.23880 /$ nhij-16000S1-007

\section{Abstract}

The objective of this study was to reflect on the scientific production in the health area in a semester of the COVID-19 pandemic. It is a reflection based on a survey carried out in the PUBMED and SCIELO databases, through the descriptors and operators: [Covid-19] or [coronavirus], between December 2019 and June 2020. The analysis was by descriptive statistics. There was a concentration of scientific production in the country China and in the thematic treatments. We found a gap in research in the field of Nursing, known to be involved in all direct and indirect care, in assistance, teaching and management. Strengthening nursing while science requires scientific production in established databases.

Keywords: Covid 19; Coronavirus

\section{Introduction}

At the end of 2019, China faced an outbreak of - pneumonia infected bySARS-CoV-2, later recognized by the Coronavirus family. According to the description of the pathology in 2019, the disease was called COVID-19. In January 2020, it was observed that person-to-person transmissibility required control measures to decrease spread. However, in March 2020, WHO recognized the pandemic, after confirmation from infected people around the world. In March 2020, this outbreak was recognized as a pandemic, leaving several countries in a state of alert and, with this, accentuating and evidencing economic and social impacts internationally [1].

In a panorama of the pandemic, from July 2020, the two countries in greater transmission proportions are the United States (3,229,862 confirmed cases/ 134,289 deaths) and Brazil (1,845,875 confirmed cases/ 71,612 deaths) [2]. Faced with all the impact, the production of scientific studies on different themes is necessary for the prevention, control, treatment and care for people infected with SarsCov2.
In Brazil, the Federal Government presented the Annual Budget Bill (PLOA) 2020, with the aim of reducing $87 \%$ of the National Development Council's budget for Scientific and Technological Development (CNPq). In response, the Brazilian Society for the Progress of Science (SBPC) started the campaign "Why science?" in order to show society the impact that evidence-based research has on the economy and society [3].

Currently, in the European Union, $77 \%$ of scientific production is financed by the government; $60 \%$ of US scientific production is funded by the federal government, with an investment of $2.7 \%$ of GDP. While in Brazil only $1.3 \%$ of its GDP to development \& research (R\& D) [4].

Knowing the investment in research and development in Brazil, and understanding the criticality of the current situation for global public health, it is relevant to ask the main advances in knowledge about Covid-19 pandemic, considering the involvement of nursing professionals in all direct and indirect care, teaching and management. 
It was a Degree Final Project that aimed to understand the nursing scientific contribution in the first semester of the Covid-19 Pandemic.

\section{Objective}

The present study aimed to reflect on the scientific production in the field of health and the scientific contribution of nursing in the first semester of the COVID-19 Pandemic.

\section{Method}

The theoretical reflection was based on a survey in the Medical Database Publications (Pubmed) and Scientific Electronic Library Online (SciELO).

For the search, descriptors were used according to the Descriptors in Science (DeCs) and Medical Subject Headings (MESH) and Boolean operators "And" and "or" were used. We use the following search terms: [Covid-19] or [coronavirus].

The period considered for data collection was from December 2019 to June 2020. Inclusion criteria were: free full articles; Language English, Portuguese, Spanish or Italian; related to health in the Covid-19 pandemic. Exclusion criteria were: records not from peer review.
This reflection done in a quarantine period when undergraduate student couldn't collect data to other research project planned previously, was part of the process of making sense of an experience in order to learn and improve as a nursing practitioner.

In order to do this effectively, reflection involves describing, analyzing and evaluating experiences from practice in a way that could help the authors in the make sense of it.

The steps followed were critical analysis, covering problematization of the theme, interpretative reading related bibliography and own construction and conceptually grounded of the subject.

\section{Results}

At PubMed, 30 records were recovered, however seven records were excluded because there were a description of manuals, database of drugs, symptoms or protocols. At Scielo, 26 records were found, however two records were duplicated and three recovered records had no relation to the COVID 19 pandemic, not fulfilling the inclusion criteria. Table 1 presents a summary of the study design and the origin of the articles.

\begin{tabular}{|c|c|c|c|c|}
\hline \multirow{3}{*}{ Categories } & Subcategories & $\begin{array}{c}\text { SciELO (n\%) - 21 } \\
\text { articles }\end{array}$ & $\begin{array}{c}\text { PubMed (n\%) - 22 } \\
\text { articles }\end{array}$ & $\begin{array}{c}\text { Total (n\%) - 43 } \\
\text { articles }\end{array}$ \\
\hline \multirow{4}{*}{ Method } & $\begin{array}{c}\text { Experimental / quasi- } \\
\text { Experimental [5-16] }\end{array}$ & 0 & $45.45 \%$ & $23.25 \%$ \\
\cline { 2 - 5 } & Non-experimental [17-30] & $42.85 \%$ & $31.81 \%$ & $37.20 \%$ \\
\cline { 2 - 5 } & Qualitative [31-34] & $14.28 \%$ & $18 \%$ & $9.30 \%$ \\
\cline { 2 - 5 } & Review [35-46] & $42.85 \%$ & $18.18 \%$ & $30.23 \%$ \\
\hline \multirow{5}{*}{ Countries } & China [6,8-11,13-16,18,23,24,31,33] & $4.76 \%$ & $59.09 \%$ & $32.55 \%$ \\
\cline { 2 - 5 } & Brazil [12,19-22,29,30,34,40-44] & $61.90 \%$ & $4.54 \%$ & $30.22 \%$ \\
\cline { 2 - 5 } & Chile [27,28,32,38,39,45,46] & $33.33 \%$ & 0 & $16.27 \%$ \\
\cline { 2 - 5 } & USA [25,35,36] & 0 & $13.63 \%$ & $6.97 \%$ \\
\cline { 2 - 5 } & France [7,17] & 0 & $9.09 \%$ & $4.65 \%$ \\
\cline { 2 - 5 } & Italy [26,37] & 0 & $9.09 \%$ & $4.65 \%$ \\
\cline { 2 - 5 } & United Kingdom [5] & 0 & $4.54 \%$ & $2.32 \%$ \\
\hline
\end{tabular}

Table 1: Methodological design and origin of articles related to Covid-19 in Scielo and Pubmed-2020.

Table 2 shows the themes or disciplines to which the articles found refer. 


\section{Nursing \& Healthcare International Journal}

\begin{tabular}{|c|c|c|c|c|}
\hline \multirow{4}{*}{} & Cardiology [44,45] & $4.76 \%$ & 0 & $4.65 \%$ \\
\cline { 2 - 5 } & Surgery [37] & 0 & $4.54 \%$ & $2.32 \%$ \\
\cline { 2 - 5 } & Endoscopy [19] & $4.76 \%$ & 0 & $2.32 \%$ \\
\cline { 2 - 5 } & Nursing [29] & $4.76 \%$ & 0 & $2.32 \%$ \\
\cline { 2 - 5 } & Epidemiology [21,23,28,32] & $14.28 \%$ & $4.54 \%$ & $9.30 \%$ \\
\cline { 2 - 5 } & Sport [42] & $4.76 \%$ & 0 & 2.32 \\
\cline { 2 - 5 } & Immunology [31,39] & $4.46 \%$ & $4.54 \%$ & $4.65 \%$ \\
\cline { 2 - 5 } & Intensive [20,37] & $9.52 \%$ & 0 & $4.65 \%$ \\
\cline { 2 - 5 } & Maternal and child [47] & $4.76 \%$ & 0 & $2.32 \%$ \\
\cline { 2 - 5 } & Dentistry [22,27,30,33,38,46] & $28.57 \%$ & 0 & $13.95 \%$ \\
\cline { 2 - 5 } & Public Health [40] & $4.76 \%$ & 0 & $2.32 \%$ \\
\cline { 2 - 5 } & Mental Health [13] & 0 & $4.54 \%$ & $2.32 \%$ \\
\cline { 2 - 5 } & Symptoms [26,35,36] & 0 & $13.63 \%$ & $6.97 \%$ \\
\cline { 2 - 5 } & Technology [16,18] & $4.76 \%$ & $50.00 \%$ & $27.90 \%$ \\
\cline { 2 - 5 } & Treatment [5-12,14,15,17,43] & $4.76 \%$ & 0 & $2.32 \%$ \\
\cline { 2 - 5 } & Trauma [34] & 0 & $9.09 \%$ & $4.65 \%$ \\
\hline
\end{tabular}

Table 2: Production theme related to COVID-19 at Scielo and Pubmed- 2020.

\section{Discussion}

There are currently more than 202 thousand scientific productions regarding the coronavirus [48]; however, between 2019 and 2020 there are 51,659 published articles addressing the current pandemic. We analyzed a small sample of 43 articles [5-48] retrieved from the databases Scielo and Pubmed published since January 2020.

From the perspective of a Brazilian nursing undergraduate student, the interpretation of the table it is possible to identify that the greatest scientific production is not only in Latin America, but also in China with 14 published articles, accounting for $31.82 \%$ of the whole, as well as Brazil, which despite corresponding to $31.82 \%$, worldwide we represent only $0.27 \%$ of the science production on COVID-19 [48]. On the other hand, countries that have little prominence in the studied bases, worldwide are responsible for more than $90 \%$ of science produced, just like the USA and European countries [48].

Interesting data from the survey carried out relate to the production of science. Although they havelittle representation in the study sample, we list some relevant themes to guide the discussion: Pandemic Social impact, patient and worker security, impact on mental health, maternal and child health impact of the pandemic; and nursing.

Approximately $40 \%$ of published articles refer to treatments, vaccines, immune response, and technologies used. Despite making up a large part of the sample, the articles report initial study phases. On the other hand, studies that delve into the historical aspect and in the impact of social difference, they have low representativeness in the studied bases, despite its relevance. It is possible to reflect on the representativeness of the theme in parallel to representativeness that the most vulnerable population has on a daily basis, which is also low.

Only one article $(2.32 \%)$ of the 43 studies analyzed is focused on the public health. This study aims to point out the social determinants imposed long before the pandemic, but which reflect the number of contaminated, dead, and unemployed and more unmeasurable consequences [40].

In New York, prevalence and mortality estimates pointed to greater disparity among African Americans, browns and whites. The mortality rate in the African American population is higher than in the white population [49]. The causes of this evident disparity are: historical social determinants, economic and / or educational disadvantage, access to health qualified health, among others [50]. Just one Brazilian article [40] addresses and discusses the disparity among the mortality relating it to structural racism.

This social problem extends to health professionals who work in the front line. In May 2020 the world accounted for 236 deaths of nursing professionals. Currently in Brazil 
there are 98 deaths from coronavirus and more than three thousand professionals contaminated. So, during May 2020, Brazil concentrates $41 \%$ of the total deaths of professionals in the world [51]. Scientific production addressing worker protection and safety also had little representativeness in the sample; only four articles [20,22,27,29], three of them were addressed dental point of view and only one was at nursing's point of view. Among these articles, two reporting of sanitation protocols implementation, altered and spent work flow greater with personal protective equipment (PPE). In Brazil, the Ministry of Health has been working to distribute around 80 million personal protective equipment, and despite these efforts, the number of professionals contaminated remains increasing [52]. Personal protective equipment is designated for the prevention of risks that threaten the health of the professional [53].

In addition to the concern to be contaminated, health workers also deal with the increased workload, for two interconnected reasons: first, by the outbreak of Covid with growing number of cases; second, by the number of professionals on medical sick leave (risk group or contracted the disease) [54]. In Brazil, it is estimated that between 122 thousand and 365 thousand workers will be away from work due to contagion or death due to illness [55], consequently, again leading to an increase in the workload of healthcare professionals.

Despite the increase in workload already mentioned a study in Portugal points out the significant increase in anxiety and stress in working professionals. Such stress is caused due to the lack of safe equipment, an increase in the workload, the lack of team, and the fear of exposing family members to risk as well [54].

Since only four articles [20,22,27,29] addressed the safety of the professional and patient, it is a subject that lacks attention and new studies to guide improvements in the current field of work, and provide greater security for professionals working in the pandemic, aiming to reduce their insecurities, and the number of infected.

Even though in non-scientific publications, such as news sites and social networks, the topic of training in safe dressing and undressing PPE has been widely exposed in Brazilian reality. Studies on teaching methods used for the use of PPE would be relevant, considering institutional indicators of contamination of professionals by Sarscov- 2 associated with different training strategies.

Physical and psychological illness, as well as emotional suffering, although exposed by social networks and media, was not representative among the studies considered. Researchers from Wuhan suggest that nurses exposed to
COVID-19 are at higher risk of developmental suffering and may need support and psychological intervention [56].

Within order to reduce this impact on the nursing team, mental health professionals in Wuhan are organizing a contingency plan, establishing teams of psychological intervention and providing psychological services and incentive to physical activities [57], since physical activities promote quality of life by decreasing the stress and anxiety [58]. It is noteworthy that the symptoms of mental suffering are not restricted to the health team, however they are verified in the population that, being in social isolation, they can experiences symptoms of stress, confusion and anger, which worsen as isolation persists [59]. Although the practice of physical activity is beneficial to health professionals and general population, this area was also affected by the pandemic.

The Research Institute Sports Intelligence (IPIE) emphasizes that the practice of sports (collective and individual) of high income increase the possibility of contagion, threatening public health. One of the articles considered whether the decision to postpone the Olympics 2020 was hasty or not. Second IPIE sports competitions should not be encouraged until the pandemic is following reasons: agglomeration of people from different countries and athlete's exposure to greater risk of contagion, since your immune system is weakened after sports high potential [60].

Another theme that was not considered in the sample of studies was the impact on Maternal and Child health. Only one article [47] addressed the topic. In this study, researchers raised the possible need to isolate the puerperal woman from the newborn for at least 14 days- in case of suspicion or confirmation of covid-19. Such isolation also applies to the breastfeeding, as they still lack evidence about the presence of SARS-CoV-2 in breast milk and in the placenta of pregnant women with COVID-19 [47]. Such an intervention affects the mother and the newborn in different ways. The newborn can stay deficient in essential nutrients and immunoglobulins for the first months of life, as long as breast milk is responsible for part of the baby's immune system. It worsens this reality, the lack of skin to skin (mother and child) in the first minutes of life, which influence the colonization of the NB, the bond and the maintenance of physiological factors of the NB [61]. For the puerperal woman, the impacts of not breastfeeding also have important implications as milk stasis in the breast, in addition to the frustration of not being able to breastfeed [62]. With regard to the scientific production of nursing, only one article [29] was found in the theme of nursing performance in facing the pandemic. Others articles only touched on the theme from the point of view of other disciplines. 
In Brazil, nursing is the second largest working class with 2,336,862 registered nurses counting the total number of assistants, technicians and nurses by region [52]. Although the magnitude of our workforce, at a scientific level, we are responsible for less than 3\% (from all over the world) of science produced about the coronavirus and its implications, despite have essential performance and be cited in more than $50 \%$ of the analyzed articles. In collaboration with the World Health Organization and the International Health Council Nurses, The global "Nursing NOW" campaign strives to raise the profile and status of nursing as a category.

The approvals of a national minimum wage for nursing categories and weekly shift [63]. Nursing is responsible for maintaining the most common areas of care, such as: treatment, surveillance and health education, management of medical records and, finally, responsibility for general maintenance of the service; is also responsible for new functions to the as protocols and guidelines are updated (adaptations based on science) that are often complex, resulting in advances in new diagnostic methods and treatment.

Scientific production guides and qualifies nursing care and also offers the opportunity to deconstruct outdated knowledge and build with knowledge and practices updated [64]. Quality of university education in undergraduate and graduate courses can be determinants in the quantity and quality of the research [65]. Brazilian scientific production on the current pandemic represents only $0.60 \%$, while the USA represents 98\%, which is an investment reflection [48].

The main function of nursing research is to contribute to the development of work processes for nursing practice, which will allow nursing to obtain better results in care, teaching and management [66].

\section{Final Considerations}

This study contributed to the analysis of a sample of scientific productions in the first pandemic semester, and may guide future researchers on this topic. In view of the involvement of nursing in care, teaching and management processes, it is considered urgent to develop studies that allow advances in the practice of nursing and benefit both to the sick people by Covid19 and to the workers of this profession.

The reflections that emerged from the analysis of the studies brought the opportunity to observe the impacts caused by the pandemic in several areas. We find the accentuation of research on treatments, diagnostic technologies, immune response and vaccines, with high representativeness.
On the other hand, there are themes and areas that lack knowledge and investment. The areas of maternal and child use of EPIS, scientific productions of the nursing and the social impact of the pandemic have few appearances in the Latin American databases American. This review also provided a reflection on the investments that Science Brazilian government receives, which consequently reflects the amount of scientific advances in the country.

In this way, it is important to encourage research on such subjects for appropriation and practical application of future discoveries; including and mainly in the area of nursing which has little scientific role and great role in the front line.

\section{References}

1. (2020) Fact Sheet COVID-19 - PAHO and WHO Office in Brazil. OPAS.

2. (2020) Coronavirus disease (COVID-19) Weekly Epidemiological Update and Weekly Operational Update. WHO.

3. (2019) For what Science? Campaign raises awareness of the importance of research in Brazil. Brazilian Society for the Progress of Science.

4. (2019) In developed countries, the money that finances science at the university is public. Jornal da USP.

5. Cao B, Wang Y, Wen D, Liu W, Wang J, et al. (2020) A Trial of Lopinavir-Ritonavir in Adults Hospitalized with Severe Covid-19. N Engl J Med 382(19): 1787-1799.

6. Wang Y,Zhang D, Du G,DuR,ZhaoJ, etal.(2020) Remdesivir in adults with severe COVID-19: a randomised, doubleblind, placebo-controlled, multicentre trial. Lancet 395(10236): 1569-1578.

7. Plaze M, Attali D, Petit AC, Blatzer M, Loriere ES, et al. (2020) Repurposing chlorpromazine to treat COVID-19: The reCoVery study. Encephale 46(3): 35-39.

8. Ye Q, Wang H, Xia X, Zhou C, Liu Z, et al. (2020) Safety and efficacy assessment of allogeneic human dental pulp stem cells to treat patients with severe COVID-19: structured summary of a study protocol for a randomized controlled trial (Phase I / II). Trials 21(1): 520.

9. Huang M, Tang T, Pang P, Li M, Ma R, et al. (2020) Treating COVID-19 with Chloroquine. J Mol Cell Biol 12(4): 322325 .

10. Liu K, Zhang W, Yang Y, Zhang J, Li Y, et al. (2020) Respiratory rehabilitation in elderly patients with COVID-19: A randomized controlled study. Complement 
Ther Clin Pract 39: 101166.

11. Hung IF, Lung KC, Tso EYK, Liu R, Chung TW, et al. (2020) Triple combination of interferon beta-1b, lopinavirritonavir, and ribavirin in the treatment of patients admitted to hospital with COVID-19: an open-label, randomised, phase 2 trial. Lancet 395(10238): 16951704.

12. Borba MGS, Val FFA, Sampaio VS, Alexandre MAA, Melo GC, et al. (2020) Effect of High vs Low Doses of Chloroquine Diphosphate as Adjunctive Therapy for Patients Hospitalized With Severe Acute Respiratory Syndrome Coronavirus 2 (SARS-CoV-2) Infection: A Randomized Clinical Trial. JAMA Netw Open 3(4): 208857.

13. Wei N, Huang B, Lu S, Hu J, Zhou X, et al. (2020) Efficacy of internet-based integrated intervention on depression and anxiety symptoms in patients with COVID-19. J Zhejiang Univ Sci B 21(5): 400-404.

14. Liu K, Chen Y, Wu D, Lin R, Wang Z, et al. (2020) Effects of progressive muscle relaxation on anxiety and sleep quality in patients with COVID-19. Complement Ther Clin Pract 39: 101132.

15. Tang W, Cao Z, Han M, Wang Z, Chen J, et al. (2020) Hydroxychloroquine in patients with mainly mild to moderate coronavirus disease 2019: open label, randomised controlled trial. BMJ 369: 1849.

16. Li J, Wang X, Huang X, Chen F, Zhang X, et al. (2020) Application of CareDose 4D combined with Karl 3D technology in the low dose computed tomography for the follow-up of COVID-19. BMC Med Imaging. 20(1): 56.

17. Molina J, Delaugerre C, Le GJ, Lima BM, Ponscarme D, et al. (2020) No evidence of rapid antiviral clearance or clinical benefit with the combination of hydroxychloroquine and azithromycin in patients with severe COVID-19 infection. Med Mal Infect 50(4): 384.

18. Huang Z, Zhao S, Xu L, Chen J, Lin W, et al. (2020) Imaging features and mechanisms of novel coronavirus pneumonia (COVID-19): Study Protocol Clinical Trial (SPIRIT Compliant). Medicine (Baltimore) 99(16): 19900.

19. Franzini TAP, Kotinda A, Moura DTH, Badana MLV, Medeiros MS, et al. (2020) Approach to Endoscopic Procedures: A Routine Protocol from a Quaternary University Referral Center Exclusively for Coronavirus Disease 2019 Patients. Clinics 75: e1989.

20. Correa TD, Matos GFJ, Bravim BA, Cordioli RL, Garrido
APG, et al. (2020) Intensive support recommendations for critically-ill patients with suspect or confirmed COVID-19 infection. Einstein (São Paulo) 18: 1-9.

21. Rezende LFM (2020) Adults at high-risk of severe coronavirus disease-2019 (Covid-19) in Brazil. Revista de Saude Publica 54.

22. Martins-Chaves RR, Gomes CC, Gomez RS (2020) Immunocompromised patients and coronavirus disease 2019: a review and recommendations for dental care. Brazilian Oral Research 34.

23. Dai M, Liu D, Liu M, Zhou F, Li G, et al. (2020) Patients with Cancer Appear More Vulnerable to SARS-CoV-2: A Multicenter Study during the COVID-19 Outbreak. Randomized Controlled Trial 10(6): 738-791.

24. Zhu FC, Li YH, Guan XH, Hou LH, Wang WJ, et al. (2020) Safety, tolerability, and immunogenicity of a recombinant adenovirus type-5 vectored COVID-19 vaccine: a doseescalation, open-label, non-randomised, first-in-human trial. The Lancet 395(10240): 1845-1854.

25. Modjarrad K, Roberts CC, Mills KT, Castellano AR, Paolino K, et al. (2020) Safety and immunogenicity of an anti-Middle East respiratory syndrome coronavirus DNA vaccine: a phase 1, open-label, single-arm, doseescalation trial. The Lancet Infect Dis 19(9): 1013-1022.

26. Ferrarese C, Silani V, Priori A, Galimberti S, Agostoni $\mathrm{E}$, et al. (2020) An Italian multicenter retrospectiveprospective observational study on neurological manifestations of COVID-19 (NEUROCOVID). Neurol Sci 41(6): 1355-1359.

27. Boin-Bakit C, Melián-Rivas A (2020) Dental Care for COVID-19 Positive Patients. What to do in an Emergency?. Int J Odontostomatology 14(3): 321-324.

28. Díaz-Narváez V, Martín-Roldán DS, Calzadilla-Núñez A, Martín-Roldán PS, Parody-Muñoz, A, et al. (2020) Which curve provides the best explanation of the growth in confirmed COVID-19 cases in Chile? Rev Latino-Am Enfermagem 26.

29. Marques LC, Cristini Lucca D, Orlandini Alves E, Fernandes GCM, Do Nascimento KC (2020) Covid-19: Cuidados De Enfermería Para La Seguridad En La Atención Del Servicio Pre-Hospitalario Móvil. Texto \& Contexto - Enfermagem 29.

30. Montalli VAM, Montalli GAM, Gomes FM, Sayuri S, Tondini LM, et al. (2020) Individual dental biosafety barrier: an alternative in times of covid-19. Preliminary study. Revista Gaúcha de Odontologia 68. 
31. Ma A, Cheng J, Yang J, Dong M, Liao X, Kang Y (2020) Neutrophil-to-lymphocyte ratio as a predictive biomarker for moderate-severe ARDS in severe COVID-19 patients. Crit Care 24(1): 288.

32. Guiñez-Coelho M (2020) Impact of COVID-19 (SARSCoV-2) Worldwide, Implications and Preventive Measures in Dental Practice and its Psychological Consequences on Patients. Int J Odontostomatology 14(3): 271-278.

33. Sun J, Xu Y, Qu Q, Luo W (2020) Knowledge of and attitudes toward COVID-19 among parents of child dental patients during the outbreak. Brazilian Oral Research 34.

34. Ribeiro MAF, De-Campos T, Lima DS, Marttos AC, Pereira BM (2020) The trauma and acute care surgeon in the COVID-19 pandemic era. Revista do Colégio Brasileiro de Cirurgiões 47.

35. Basu-Ray I, Almaddah NK, Adeboye A, Soos MP (2020) Cardiac Manifestations of Coronavirus (COVID-19). StatPearls.

36. Hu K, Patel J, Patel B (2020) Ophthalmic Manifestations of Coronavirus (COVID-19). Stat Pearls.

37. Giorgi P, Villa F, Gallazzi E (2020) The management of emergency spinal surgery during the COVID-19 pandemic in Italy. Bone Joint J 102 B(6): 671-676.

38. Sepúlveda-Verdugo C, Secchi-Álvarez A, Donoso-Hofer F (2020) Considerations in Emergency Dental Care in the Context of Coronavirus COVID-19 (SARS-CoV-2). International journal of odontostomatology 14(3): 279284.

39. Pastrian-Soto G (2020) Genetic and Molecular Basis of COVID-19 (SARS-CoV-2) Mechanisms of Pathogenesis and Immune. Int J Odontostomatology 14(3): 331-337.

40. De Souza DO (2020) The COVID-19 pandemic beyond the Health Sciences: reflections on its social determination. Science \& Collective Health 25(1): 2469-2477.

41. Lima DS, Ribeiro Junior MF, Vieira-Jr HM, Campos T de, Saverio S Di (2020) Alternatives for establishing a surgical airway during the COVID-19 pandemic. Review of the Brazilian College of Surgeons 47.

42. Guerreiro R de C, Silva A, Andrade H de A, Biasibetti, Isadora Grade, et al. (2020) Was Postponing The Tokyo 2020 Olympic And Paralympic Games A Correct Decision? Rev Bras Med Esporte 26(3): 191-195.

43. Cespedes M, Souza J (2020) Coronavirus: a clinical update of Covid-19. Rev Assoc Med bras 66(2): 116-123.
44. Ferrari F (2020) COVID-19: Updated Data and its Relationship with the Cardiovascular System. Brazilian Archives of Cardiology 114(5): 823-826.

45. Ramírez-Sagredo A, Ramírez-Reyes A, Ocaranza MP, Chiong M, Riquelme JA, et al. (2020) Anti hypertensive agents in patients with COVID-19. Rev Chil Cardiol 39(1): 66-74.

46. Melián-Rivas A, Calcumil-Herrera P, Boin-Bakit C, Carrasco-Soto R (2020) Detection of COVID -19 (SARS-CoV-2) Using Saliva: A Low Invasive Diagnostic Alternative. Int J Odontostomat 14(3): 316-320.

47. Martins-Filho PR, Santos VS, Santos HP (2020) To breastfeed or not to breastfeed? Lack of evidence on the presence of SARS-CoV-2 in breastmilk of pregnant women with COVID-19. Rev Panam Salud Pública 44: e59.

48. Periódicos CAPES (2020).

49. (2020) Health NYC. COVID - 19: dados.

50. Cunningham TJ, Croft JB, Liu Y, Lu H, Eke PI, et al. (2017) Vital Signs: Racial Disparities in Age - Specific Mortality Among Blacks or African Americans - United States, 1999-2015. MMWR Morb Mortal Wkly Represent 66(17): 444-456.

51. (2020) Brazil surpasses USA in deaths of Nursing professionals by Covid-19. CF Nursing.

52. (2020) Number of professionals by region. Nursing in numbers. CF Nursing.

53. Mdo TeE. Portaria, de outubro de (2001) Alters the Regulatory Norm that deals with Personal Protective Equipment - NR6 and gives other measures 1: 1.

54. Sampaio F, Sequeira C (2020) Mental health assessment of nurses in the care of COVID-19.

55. Saúde CN de, Saúde M da (2020) Recommendation No 020.

56. JL, SM, YW, ZC, JH, et al. (2020) Factors Associated with mental health outcomes among health professionals exposed to Coronavirus disease. Network JAMA 3(3).

57. Kang LA, Yi Li, Shaohua Hu, Min Chen, Can Yang, et al. (2020) The mental health of medical workers in Wuhan, China dealing with the 2019 novel coronavirus. Lancet Psychiat 7(3): E14.

58. Bushman B (2017) Complete guide to fitness \& health. Champaign Hum Kinect 2. 
59. Brooks S, Webster R, Smith L, Woodland L, Wessely S, et al. (2020) The psychological impact of quarantine and how to reduce it: rapid review of the evidence. Lancet 395: 912-920.

60. Paraná UF (2020) Sports Intelligence proposes rules for post-pandemic resumption for each sport.

61. Matos TA, Souza MS de, Santos EKA dos, Velho MB, Seibert ERC, et al. (2010) Early skin-to-skin contact between mother and child: meaning for mothers and contributions to nursing. Rev Bras Enferm 63(6).

62. Toma TS, Rea MF (2008) Benefits of Amametation for the Health of women and children: an essay on evidence
24(2).

63. (2019) Cofen defines launch of the Nursing Now Campaign.

64. Sousa LD de, Lunardi Filho WD, Lunardi VL, Santos SSC, Santos CP dos (2011) The scientific production of nursing about the clinic: an integrative review Rev Esc Enferm USP 45(2): 483-488.

65. Domenico EBL De, IDE CAC (2003) Evidence-based nursing: principles and applicability. Rev Latino-Am Enferm 11(1): 115-118.

66. Dickoff J, James P (1968) Researching research's role in theory development. Nurs Res 17(3): 204-205. 